\title{
Correlation between clinical features and total maturation score by magnetic resonance imaging in very low birth weight premature infants with brain injury
}

\author{
Dalin Zhu', Manxia Wang ${ }^{1}$, Fan Feng ${ }^{2}$, Nan $\mathrm{Nan}^{3}$, Yuefen Liu ${ }^{3}$, Jinyun Shi ${ }^{4}$, Baohong Mao \\ ${ }^{1}$ Department of Neurology, Lanzhou University Second Hospital, Lanzhou, China; ${ }^{2}$ Department of Reproductive Medicine Center, Gansu Province \\ Maternity and Child Care Hospital, Lanzhou, China; ${ }^{3}$ Department of Early Childhood Development Center, Gansu Province Maternity and Child \\ Care Hospital, Lanzhou, China; ${ }^{4}$ Department of NICU, Gansu Province Maternity and Child Care Hospital, Lanzhou, China; ${ }^{5}$ Department of \\ Research Center, Gansu Province Maternity and Child Care Hospital, Lanzhou, China \\ Contributions: (I) Conception and design: D Zhu; (II) Administrative support: M Wang; (III) Provision of study materials or patients: F Feng, B Mao; \\ (IV) Collection and assembly of data: D Zhu, N Nan; (V) Data analysis and interpretation: Y Liu, J Shi; (VI) Manuscript writing: All authors; (VII) \\ Final approval of manuscript: All authors. \\ Correspondence to: Manxia Wang. Department of Neurology, Lanzhou University Second Hospital, No. 82 Cuiyingmen, Chengguan District, \\ Lanzhou 730030, China. Email: wmx322@aliyun.com.
}

Background: Brain injury in premature infants (BIPI) seriously affects the growth and development of preterm infants. Magnetic resonance imaging (MRI) has become an important method of assessing brain development. The aim of this study was to explore the correlation between clinical features and total maturation score (TMS) by MRI in very low birth weight (VLBW) preterm infants with brain injury at term postmenstrual age (PMA).

Methods: A retrospective cohort of 65 cases of BIPI with VLBW and 40 normal control cases were included, and all cases underwent MRI examination. The 2 groups were assessed in terms of TMS and sub-parameters (myelination, cortical infolding, germinal matrix, bands of migrating glial cells), and the correlation between TMS and term PMA was also analyzed.

Results: The TMS of the BIPI group was lower than that of the control group $(\mathrm{P}<0.01)$. The differences in myelination and cortical infolding were statistically significant $(\mathrm{P}<0.01)$. No significant differences in the germinal matrix and bands of migrating glial cells were found. The linear regression equation showing a positive correlation between TMS and term PMA in normal preterm infants was $\mathrm{y}=1.164 \mathrm{x}-28.888(\mathrm{t}=9.478$, $\mathrm{P}=0.000)$.

Conclusions: TMS by conventional cranial MRI can objectively reflect the brain maturity and brain damage of premature infants, and is related to the term PMA.

Keywords: Brain injury; premature infants with very low birth weight; magnetic resonance imaging (MRI); total maturational scores; brain development.

Submitted Dec 07, 2020. Accepted for publication Feb 21, 2021.

doi: 10.21037/apm-21-55

View this article at: http://dx.doi.org/doi: 10.21037/apm-21-55

\section{Introduction}

The incidence of brain injury in premature infants (BIPI) has been reported to be as high as $10-20 \%(1-3)$. Therefore, early diagnosis, treatment, and intervention are of great importance for children with brain injury (4).
Magnetic resonance imaging (MRI) is a high-resolution soft tissue examination method which is safe and has no risk of radiation damage. At present, MRI is widely used in the imaging of neonates and premature infants $(5,6)$. The total maturation score (TMS) of MRI is a commonly 
used scoring system to evaluate the maturity of brain development. Most previous studies have not grouped preterm infants by birth weight, and there are few reports on very low birth weight (VLBW) preterm infants. This study further explores the application value of TMS with MRI in the evaluation of brain injury in VLBW preterm infants at term postmenstrual age (PMA), and aims to discover more effective methods for early diagnosis.

We present the following article in accordance with the MDAR checklist (available at http://dx.doi.org/10.21037/ apm-21-55).

\section{Methods}

\section{Patients and data}

A retrospective cohort of 65 VLBW preterm infants with brain injury from the neonatal intensive care unit (NICU) of Gansu Province Maternity and Child Care Hospital between October 2013 and January 2019 was enrolled, with gestational age less than 37 weeks and birth weight less than $1,500 \mathrm{~g}$.

The case group met the following inclusion criteria: (I) MRI examination of the brain was abnormal, with intracranial hemorrhage and white matter damage; (II) the newborn had severe intrauterine distress and umbilical cord around the neck. Pregnant women had placenta previa, premature rupture of membranes, placental abruption, history of amniotic fluid contamination, hypertension, diabetes, and hyperthyroidism; (III) the newborn had clinical manifestations such as convulsions, increased intracranial pressure, abnormal primitive reflexes, changes in consciousness, and hypotonia.

The control group consisted of 40 normal preterm infants admitted to hospital with feeding intolerance and scalp hematoma without obvious clinical manifestations of brain injury and normal MRI examination results. The clinical follow-up showed no abnormalities for 12 months.

Both groups of infants underwent MRI examination at 37-41 weeks at term PMA, and were followed up to 12 months for neurobehavioral assessment using the Gesell Developmental Scale. Informed consent was obtained from the guardians (parents) of all children for each examination. This study was approved by the Ethics Committee of Gansu Provincial Maternity and Child Care Hospital (No. 2020 GSFY [5]). The clinical data collected were as follows: gender (male/female), gestational age (weeks), birth weight (g), weight at term PMA (g), delivery method (natural birth/cesarean section), twins (yes/no), first delivery (yes/ no), in vitro fertilization-embryo transfer (IVF-ET) (yes/ no), Apgar 1- and 5-minute score, and mother's age (years). All procedures performed in this study involving human participants were in accordance with the Declaration of Helsinki (as revised in 2013).

\section{Study methods}

\section{Brain MRI}

The Siemens AVANTO 1.5T MR scanner with head surface coil was used. The parameter settings were T1WI (T1 weighted image, SE sequence) TRA: TR $500 \mathrm{~ms}$, TE $11 \mathrm{~ms}$, FOV $160 \mathrm{~mm}$, layer thickness $4 \mathrm{~mm}$, voxel $0.7 \times 0.6 \times 4.0 \mathrm{~mm}^{3}$; T1WI (T1 weighted image, SE sequence) SAG: TR $450 \mathrm{~ms}$, TE $8.7 \mathrm{~ms}$, FOV $230 \mathrm{~mm}$, layer thickness $4 \mathrm{~mm}$, voxel $1.0 \times 0.9 \times 4 \mathrm{~mm}^{3}$; T1 [turbo invasion recovery magnitude (TIRM) dark-fluid sequence] TRA: TR 1,700 ms, TE $8.1 \mathrm{~ms}$, FOV $230 \mathrm{~mm}$, layer thickness $4 \mathrm{~mm}$; T2WI (T2 weighted image, blade sequence): TR 4,000 ms, TE $100 \mathrm{~ms}$, layer thickness $4 \mathrm{~mm}$, FOV $160 \mathrm{~mm}$, voxel $0.8 \times 0.8 \times 4.0 \mathrm{~mm}^{3}$; T2WI (T2 weighted image) FLARI sequence: TR 7,500 ms, TE $100 \mathrm{~ms}$, voxel $0.8 \times 0.8$ $\times 4.0 \mathrm{~mm}^{3}$; DWI (diffusion weighted image) sequence: TR 3,400 ms, TE $100 \mathrm{~ms}$, FOV $230 \mathrm{~mm}$, layer thickness $4 \mathrm{~mm}$, voxel $1.3 \times 1.2 \times 4 \mathrm{~mm}^{3}$; SWI (susceptibility weighted image) sequence T2WI: TR $49 \mathrm{~ms}$, TE $40 \mathrm{~ms}$, FOV $200 \mathrm{~mm}$, layer thickness $4 \mathrm{~mm}$, voxel $0.7 \times 0.6 \times 1.6 \mathrm{~mm}^{3}$.

\section{MRI diagnostic criteria}

The diagnosis and classification of BIPI with VLBW included white matter damage and intracranial hemorrhage. The diagnostic classification of intracranial hemorrhage according to the Papile evaluation criteria (7) was as follows: grade I, germinal matrix hemorrhage; grade II, germinal matrix hemorrhage and breaks into the ventricle, but not accompanied by ventricular expansion; grade III, germinal matrix hemorrhage and breaks into the ventricle, accompanied by ventricular dilatation; grade IV, intraventricular hemorrhage accompanied by hemorrhage in the brain parenchyma around the ventricle. For white matter damage diagnostic classification criteria, the Miller classification (8) was used. According to T1WI performance, mild: focal punctate hyperintensity, lesions $\leq 3$, or lesions $<2 \mathrm{~mm}$; moderate: multifocal punctate or patchy hyperintensity, lesions $>3$, or lesions $>2 \mathrm{~mm}$; severe: the extent of the lesion was larger than $5 \%$ of the white matter around the ventricle of each cerebral hemisphere. 
TMS evaluation and assessment standards

Using the TMS (9), 4 parameters were observed in the brain MRI images: myelination (M), cortical infolding (C), germinal matrix (GM), and bands of migrating glial cells (B). Each parameter was quantified as described in the literature (10), myelination went up to a score of 7 , cortical infolding went up to 6 , germinal matrix went up to 4 , and bands of migrating glial cells went up to 4 , for a total score of 21 . The evaluation of myelination and germinal matrix required complete T1WI and T2WI axial images, while cortical infolding and bands of migrating glial cells only needed to be imaged at the level of the parallel flat interforamen. Myelination required assessment on both T1WI and T2WI. Two senior radiologists independently reviewed the scans and performed the scoring, and the average of the 2 was taken as the final score.

\section{Neurobehavioral follow-up and assessment criteria}

All cases in the study were followed up at least once, and the follow-up times were 3, 6, and 12 months after birth. The follow-up included head MRI and Gesell Developmental Scale evaluation. The results of neurobehavioral development were subject to the results of the 12 months follow-up.

For the Gesell Developmental Scale, premature infants were corrected to 40 weeks of gestational age to calculate the developmental quotient (DQ), and 5 energy zone indicators were assessed: adaptability $(\mathrm{AB})$, gross motor movement (GM), fine motor movement (FM), language (L), and social behavior (SB). According to the DQ calculation method, the DQ value for each case was obtained. For DQ quality control and grading, the examiners were specially trained with relevant qualifications to blindly and uniformly use the evaluation tools, equipment, and environment, and strictly followed the scale manual. DQ $>75$ indicated normal development, and $\leq 75$ indicated mental retardation.

\section{Data analysis and statistics}

The obtained questionnaire data was collected on Excel as a data file, and SPSS19.0 software was used for statistical analysis. Differences between measurement data groups were first compared with an independent sample $t$-test to compare their overall differences. If normality and homogeneity of variance were satisfied, then the independent samples $t$-test was used to compare between groups. If normality and homogeneity of variance were not satisfied, then the two independent samples MannWhitney $\mathrm{U}$ test was used. Linear regression analysis was used to analyze the linear dependence of the measurement data. The differences between groups of count data were compared with the $\chi^{2}$ test. $\mathrm{P}<0.05$ was considered statistically significant.

\section{Results}

\section{Clinical data of the BIPI group and the control group}

In this study, a total of 65 cases of BIPI with VLBW were enrolled, including 38 males and 27 females. There were 40 preterm infants in the control group, including 26 males and 14 females. The 2 groups had statistical differences in gestational age at birth, birth weight, mode of delivery (normal delivery/cesarean section), first delivery, and Apgar score at 1 minute and 5 minutes. There were no statistical differences in gender, weight at term PMA, twins, IVF-ET, and mother's age (Table 1, Figure 1).

\section{Linear regression analysis of TMS and PMA in the control group}

Using linear regression analysis, with TMS as the dependent variable and PMA as the independent variable, a positive correlation was found between TMS and PMA $(\mathrm{P}<0.01)$. The linear regression equation was $\mathrm{y}=1.164 \mathrm{x}-28.888$ $(\mathrm{t}=9.478, \mathrm{P}=0.000)$ (Figure 2).

\section{The relationship between the TMS of the BIPI with VLBW group and the control group}

The TMS of the BIPI group was significantly lower than that of the control group $(\mathrm{P}=0.005)$ (Figure 3). MRI shows TMS score is low in the case with subependymal hemorrhage (Figure 4), and lagged behind the control group (Figure 5). When the individual components of TMS were analyzed between the 2 groups, myelination $(\mathrm{P}=0.032)$ and cortical infolding $(\mathrm{P}=0.006)$ in the BIPI group lagged behind the control group, MRI shows myelination and cortical infolding scores is low in the case with intraparenchymal hemorrhage (Figure 6), and lagged behind the control group (Figure 5).There were no significant differences in germinal matrix $(\mathrm{P}=0.263)$ and the bands of migrating glial cells $(\mathrm{P}=0.894)$ between the 2 groups (Table 2).

\section{Discussion}

The survival rate of BIPI with VLBW has increased in 
Table 1 Clinical data of the BIPI group and the control group

\begin{tabular}{|c|c|c|c|c|}
\hline Characteristics & BIPI group ( $n=65)$ & Control group $(n=40)$ & $\chi^{2} / \mathrm{t}$ value & $P$ value \\
\hline Gestational age (weeks) & $29.78 \pm 1.55$ & $33.25 \pm 2.60$ & $-6.016(z)$ & 0.000 \\
\hline Birth weight (g) & $1,252.31 \pm 127.28$ & $1,929.00 \pm 582.36$ & $-9.049(z)$ & 0.000 \\
\hline Weight at term PMA (g) & $2,834.62 \pm 148.72$ & $2,884.00 \pm 216.25$ & $-1.593(\mathrm{z})$ & 0.111 \\
\hline Twins (yes/no) & $11 / 54$ & $10 / 30$ & 1.010 & 0.315 \\
\hline First delivery (yes/no) & $25 / 40$ & $24 / 16$ & 4.615 & 0.032 \\
\hline IVF-ET (yes/no) & $11 / 54$ & $5 / 35$ & 0.375 & 0.540 \\
\hline Apgar score 1 minute & $7.34 \pm 1.34$ & $8.40 \pm 0.84$ & -4.496 & 0.000 \\
\hline
\end{tabular}

BIPI, brain injury in premature infants; PMA, postmenstrual age; IVF-ET, in vitro fertilization-embryo transfer.

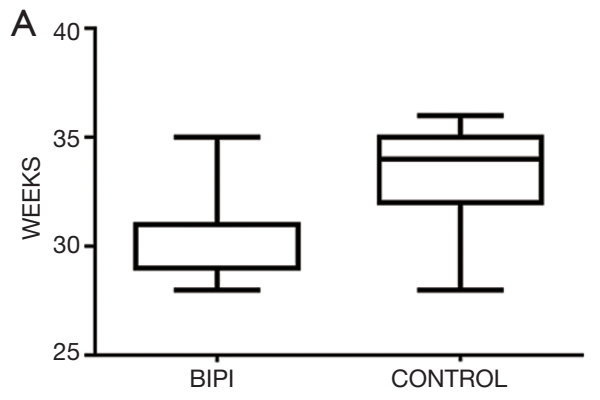

C

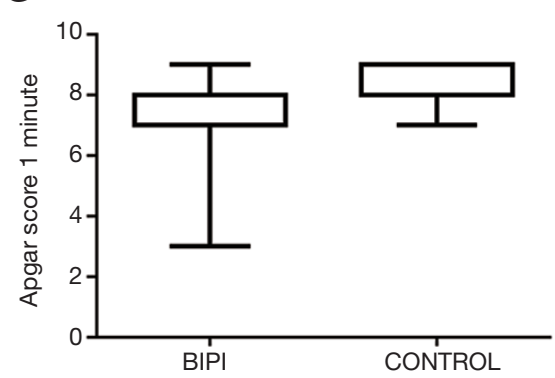

B

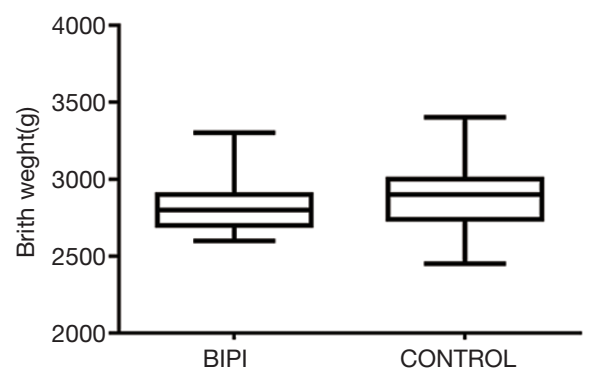

D

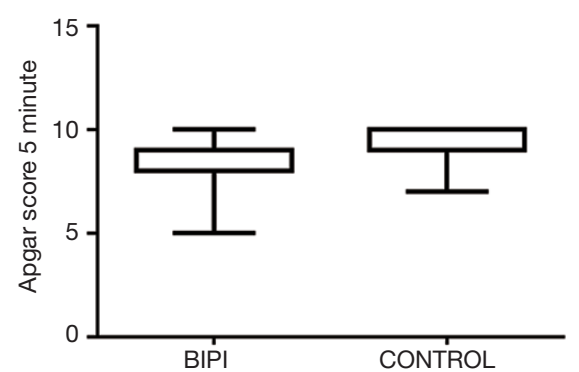

Figure 1 Clinical data of the brain injury in premature infants (BIPI) group and the control group. (A) Gestational age; (B) weight at postmenstrual age (PMA); (C) gestational age; (D) mother's age.

recent years. Some studies have shown that $10-15 \%$ of VLBW preterm infants with brain injury eventually develop cerebral palsy, and 30-60\% (9) have cognitive impairment and learning disabilities. Early diagnosis, treatment, and intervention of BIPI are therefore important measures to prevent progression. MRI is a soft tissue, multi-directional imaging method, which does not use ionizing radiation. Recently, MRI has been increasingly used in newborns and premature infants. This study further explored the correlation between MRI manifestations and the TMS of VLBW preterm infants with brain injury, seeking to enhance methods for early diagnosis, treatment, and 


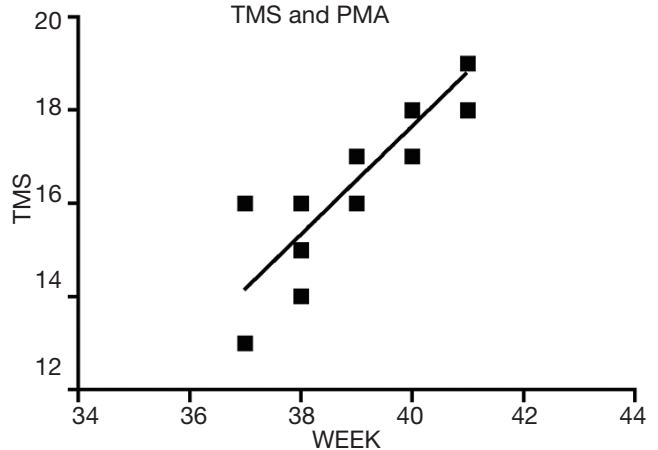

Figure 2 Linear regression analysis of total maturation score (TMS) and postmenstrual age (PMA) in the control group.

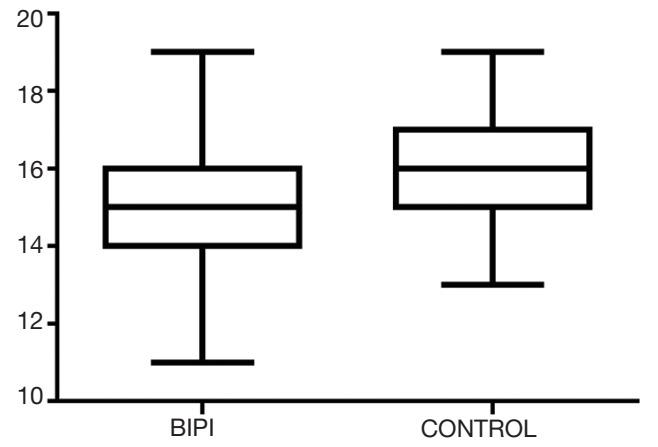

Figure 3 The total maturation score (TMS) of the brain injury in premature infants (BIPI) group and the control group.
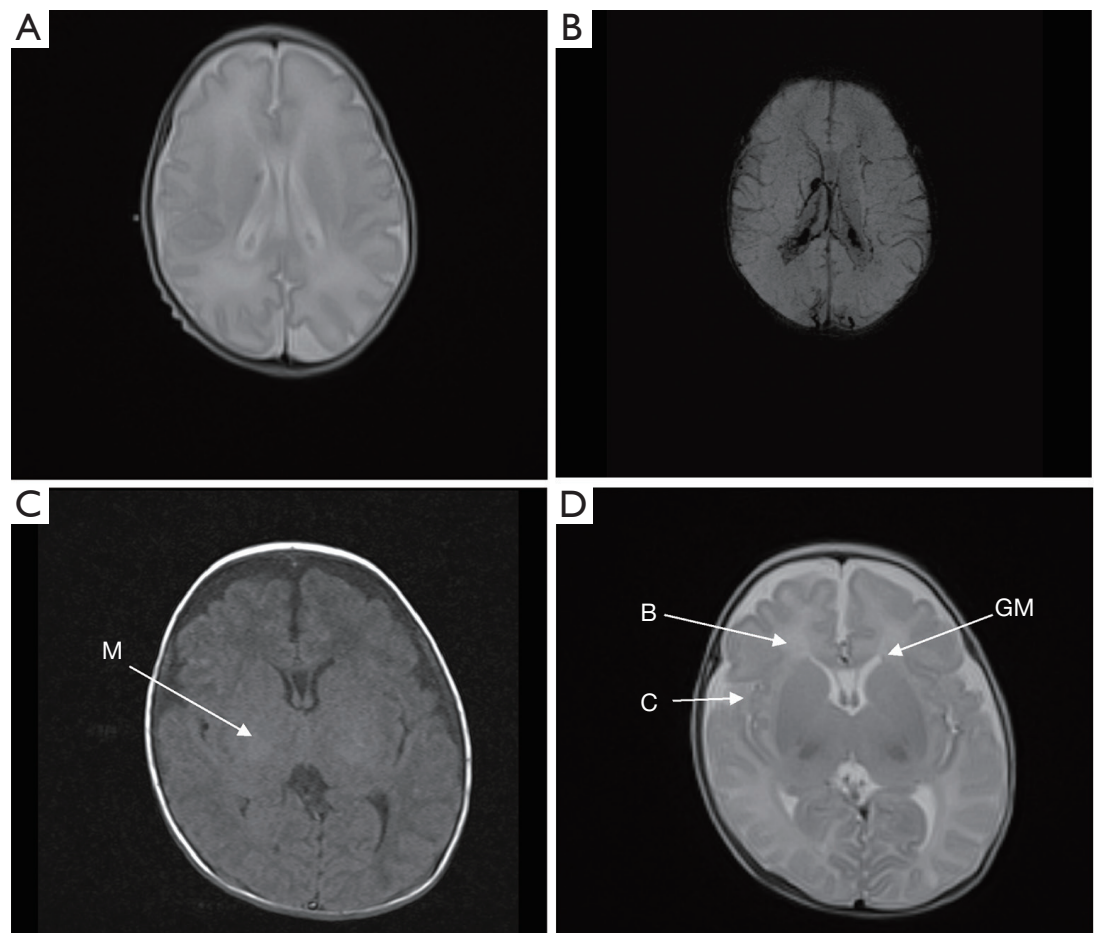

Figure 4 An infant in the brain injury in premature infants (BIPI) group at 32 weeks and 4 days gestational age. (A) Axial T2-weighted MRI image: short T2 signals can be seen in the right lateral ventricle and the posterior horns of both lateral ventricles. (B) Axial SWI sequence shows missing signal. (C) Axial T1-weighted image at 40 weeks postmenstrual age (PMA). (D) Axial T2-weighted image at 40 weeks PMA. Total maturation score (TMS) was 12, myelination score was 3, cortical infolding score was 4, germinal matrix score was 2 , and bands of migrating glial cells score was 3 .

intervention.

TMS is currently used to evaluate the maturity of the brain, and was established by Jenster et al. (10-12). TMS is positively correlated with corrected gestational age. It can objectively assess the maturity of brain development, and can help detect abnormal brain development and BIPI at different stages. It is a simple and repeatable assessment method. The results of this study showed that the TMS of the normal control group was positively correlated with term PMA, and there was a linear relationship. The linear regression equation was $\mathrm{y}=1.164 \mathrm{x}-28.888$, $(\mathrm{t}=9.478, \mathrm{P}=0.000)$. The TMS included 4 parameters 

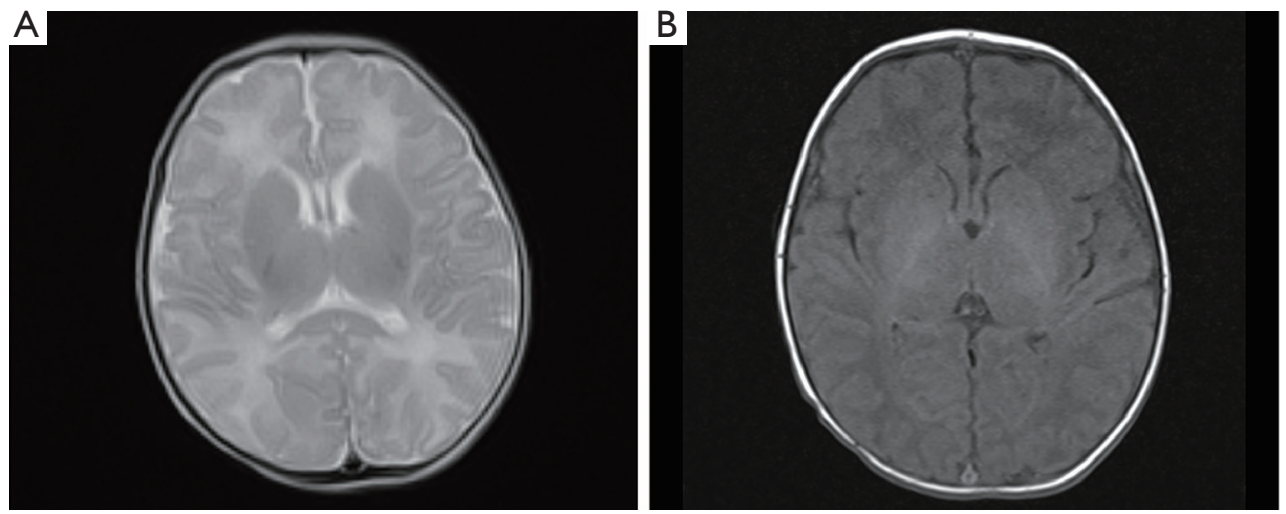

Figure 5 An infant in the control group at 33 weeks gestational age, and MRI scan at 40 weeks postmenstrual age (PMA). (A) Axial T2weighted image. (B) Axial T1-weighted image. Total maturation score (TMS) was 17, myelination score was 4, cortical infolding score was 5, germinal matrix score was 4 , and bands of migrating glial cells score was 4 .
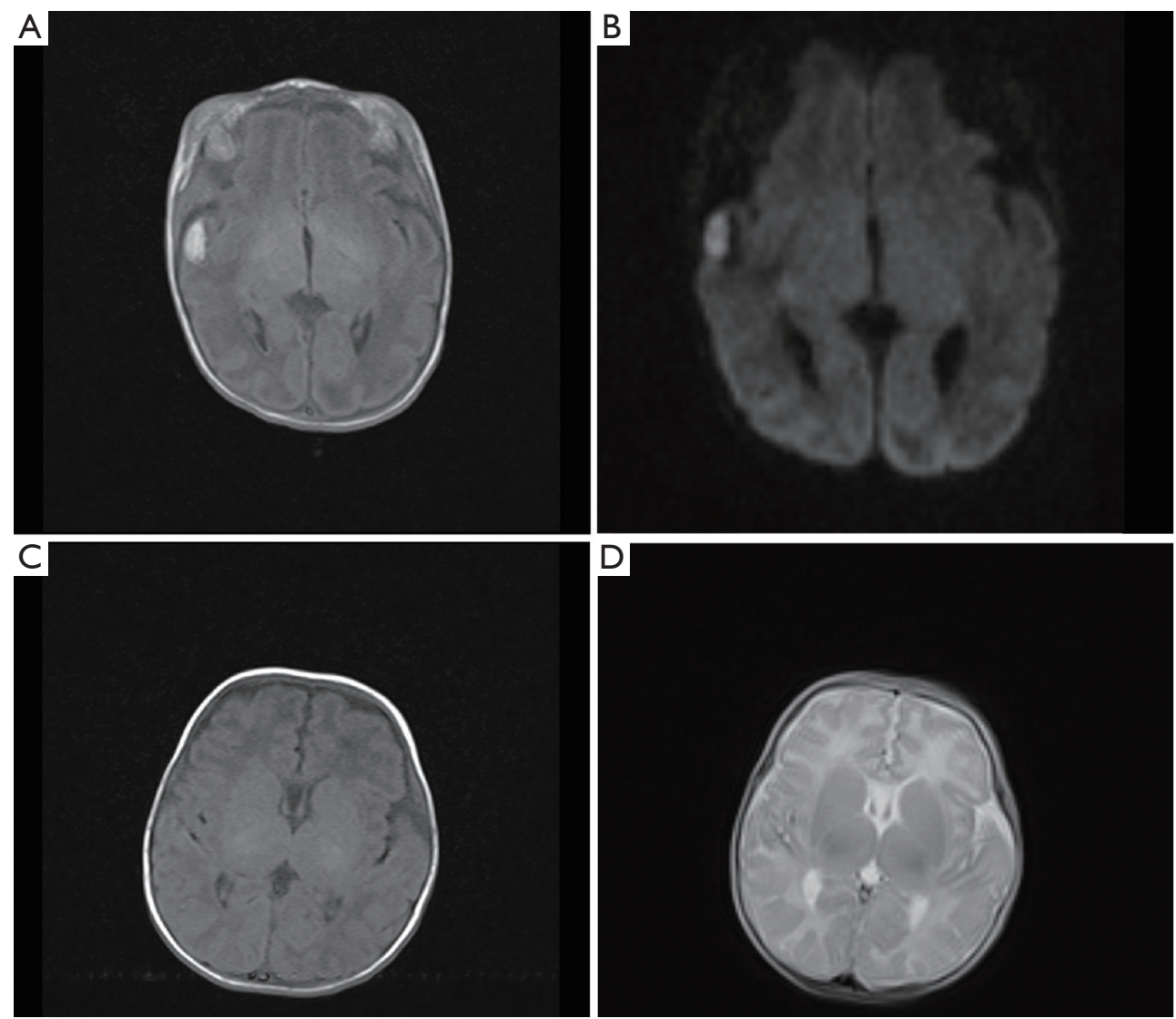

Figure 6 An infant in the brain injury in premature infants (BIPI) group at 30 weeks and 5 days gestational age. (A) Axial T1-weighted MRI image: short T2 signals can be seen in the right temporal lobe. (B) Axial diffusion weighted image (DWI) sequence shows limited diffusion. (C) Axial T1-weighted image at 39 weeks postmenstrual age (PMA). (D) Axial T2-weighted image at 39 weeks PMA. Total maturation score (TMS) was 15, myelination score was 4, cortical infolding score was 4 , germinal matrix score was 4 , and bands of migrating glial cells score was 3 . 
Table 2 TMS of the 2 groups

\begin{tabular}{lccc}
\hline Indicators & BIPI group $(\mathrm{n}=65)$ & Control group $(\mathrm{n}=40)$ & $\mathrm{P}$ value \\
\hline TMS & $14.97 \pm 1.57$ & $15.83 \pm 1.30$ & 0.005 \\
Myelination (M) & $3.92 \pm 0.72$ & $4.20 \pm 0.56$ & 0.032 \\
Cortical infolding (C) & $4.26 \pm 0.59$ & $4.56 \pm 0.50$ & 0.006 \\
Germinal matrix (G) & $3.46 \pm 0.50$ & $3.58 \pm 0.50$ & 0.263 \\
Bands of migrating glial cells (B) & $3.46 \pm 0.50$ & $3.48 \pm 0.51$ & 0.894 \\
\hline
\end{tabular}

TMS, total maturation score; BIPI, brain injury in premature infants.

(myelination, cortical infolding, germinal matrix, bands of migrating glial cells). Some studies have confirmed that TMS is a comprehensive evaluation of the 4 indicators, and there are differences in the gestational ages of the evaluation indicators, with certain time windows (13). Cortical infolding is different across gestational ages, and differences in myelination mainly occur after 38 weeks, while germinal matrix and bands of migrating glial cells only differ before 38 weeks. According to MRI images of the fetus, the germinal matrix generally disappears at 32-34 weeks, while delayed regression may occur in premature infants, but usually no later than 38 weeks (14). Among the 4 parameters, myelination and cortical infolding gradually become obvious as the brain continues to develop, and germinal matrix and bands of migrating glial cells gradually disappear with the developmental process. Woodward et al. $(15,16)$ reported that neonatal MRI abnormalities, especially white matter abnormalities, can predict cognition and motor development at 2 years old. Studies have also shown that neonatal white matter abnormality diagnosed by MRI is related to intelligence, language, executive function, and sports skills in preschool (17-19).

This study found that myelination $(\mathrm{P}=0.032)$ and cortical infolding $(\mathrm{P}=0.006)$ in the BIPI with VLBW group lagged behind the control group. This is consistent with findings from Cabaj et al. and Xing et al. (20-22), indicating that BIPI can affect cortical folding and myelination at PMA. According to the "tension-based theory" of central nervous system neurodevelopment (23), there is tension in white matter along axons. Damage to white matter in the brain may affect the morphogenesis of brain tension and change the development of the gyri. This may explain the pathology of abnormal cortical folding. Marín-Padilla (22) found through several pathological methods that the cortical neurons covering the periventricular leukomalacia undergo corticopetal, corticofugal, and association fiber destruction, leading to input deprivation and output isolation in the gray matter.

This study found that the germinal matrix $(P=0.263)$ and bands of migrating glial cells $(\mathrm{P}=0.894)$ were not significantly different between the BIPI group and the control group. This is consistent with the results of Battin et al. (23-25). The study found that the germinal matrix is the remnant of the early ventricular zone at the stage of preterm infants, which can be clearly seen on the anterior and posterior edges of the lateral ventricle. It shows high signal on T1W and low signal on T2WI. It is observed through fetal MRI images that the germinal matrix generally disappears at 32 to 34 weeks, but a small part of the caudate nucleus head and thalamus still remain in the anterior and lateral corners of the lateral ventricle. Delayed germinal matrix can occur in preterm infants, but often no later than 38 weeks. The bands of migrating glial cells are the precursors of premyelinating oligodendrocytes, which basically fade at term. In this study, there were no significant differences between the germinal matrix and the bands of migrating glial cells between the 2 groups, which may be related to the following reasons: (I) the germinal matrix and the bands of migrating glial cells were both located in the frontal lobe at approximately 30 weeks of gestational age. The white matter around the posterior horn of the lateral ventricle and the corona radiata are more likely to be damaged at this stage, and most of the frontal lobe is not easily affected. (II) The germinal matrix generally disappears at 32 to 34 weeks, but a small part of the caudate nucleus head and thalamus still remain in the anterior and lateral corners of the lateral ventricle. Delayed regression can occur in preterm infants, but usually not later than 38 weeks. In this study, most of the preterm infants whose gestational age was corrected had an average gestational age between $37-41$ weeks. 
This study has certain limitations. Firstly, the sample size of this study was small, and there were certain geographical restrictions, meaning we could not objectively evaluate the overall level of brain development in premature infants. Secondly, some children had mild brain damage and were difficult to distinguish on imaging. Therefore, larger sample size and longer follow-up studies are needed in order to better investigate the correlation between BIPI and neurological problems.

In conclusion, this study found that TMS using conventional cranial MRI can be used as an early predictor of BIPI with VLBW, which is helpful for identifying the preterm infants that require early intervention, so as to improve the neurodevelopmental and long-term prognosis of preterm infants.

\section{Acknowledgments}

Funding: The neurologic precise diagnosis and treatment base of Gansu Province international cooperation ([2017], 2nd-33). Lanzhou University clinical medicine research discipline construction plan ([2016]9).

\section{Footnote}

Reporting Checklist: The authors have completed the MDAR checklist. Available at http://dx.doi.org/10.21037/apm-21-55

Data Sharing Statement: Available at http://dx.doi. org/10.21037/apm-21-55

Conflicts of Interest: All authors have completed the ICMJE uniform disclosure form (available at http://dx.doi. org/10.21037/apm-21-55). The authors have no conflicts of interest to declare.

Ethical Statement: The authors are accountable for all aspects of the work in ensuring that questions related to the accuracy or integrity of any part of the work are appropriately investigated and resolved. Informed consent was obtained from the guardians (parents) of all children for each examination. This study was approved by the Ethics Committee of Gansu Provincial Maternity and Child Care Hospital (No. 2020 GSFY [5]). We obtained written informed consent from the guardians (parents) of all participants for the publication of this paper. All procedures performed in this study involving human participants were in accordance with the Declaration of Helsinki (as revised in 2013).

Open Access Statement: This is an Open Access article distributed in accordance with the Creative Commons Attribution-NonCommercial-NoDerivs 4.0 International License (CC BY-NC-ND 4.0), which permits the noncommercial replication and distribution of the article with the strict proviso that no changes or edits are made and the original work is properly cited (including links to both the formal publication through the relevant DOI and the license). See: https://creativecommons.org/licenses/by-nc-nd/4.0/.

\section{References}

1. Anderson PJ, Treyvaud K, Neil JJ, et al. Associations of Newborn Brain Magnetic Resonance Imaging with LongTerm Neurodevelopmental Impairments in Very Preterm Children. J Pediatr 2017;187:58-65.

2. Wang LB, He JL, Zhong Y, et al. Early evaluation of brain maturation using magnetic resonance imaging in preterm infangts. Chinese Journal of Neonatology 2016; 31:276-81.

3. Malova M, Rossi A, Severino M, et al. Incidental findings on routine brain MRI scans in preterm infants. Arch Dis Child Fetal Neonatal Ed 2017;102:F73-8.

4. Park HW, Yoon HK, Han SB, et al. Brain MRI measurements at a term-equivalent age and their relationship to neurodevelopmental outcomes. AJNR Am J Neuroradiol 2014;35:599-603.

5. Arthur R. Magnetic resonance imaging in preterm infants. Pediatr Radiol 2006;36:593-607.

6. Wu JC, Cao YC, Ma XX, et al. Meta-analysis of the effects of very premature infants and/or very low birth weight infants on brain volume in adolescents. Chinese Journal of Evidence-Based Pediatrics 2017;12:423-8.

7. Papile LA, Burstein J, Burstein R, Koffler H. Incidence and evolution of subependymal and intraventricular hemorrhage: a study of infants with birth weights less than 1,500 gm. J Pediatr 1978;92:529-34.

8. Miller SP, Cozzio CC, Goldstein RB, et al. Comparing the diagnosis of white matter injury in premature newborns with serial MR imaging and transfontanel ultrasonography findings. AJNR Am J Neuroradiol 2003;24:1661-9.

9. Childs AM, Ramenghi LA, Cornette L, et al. Cerebral maturation in premature infants: quantitative assessment using MR imaging. AJNR Am J Neuroradiol 2001;22:1577-82.

10. Jenster M, Bonifacio SL, Ruel T, et al. Maternal 
or neonatal infection: association with neonatal encephalopathy outcomes. Pediatr Res 2014;76:93-9.

11. Ramenghi LA, Fumagalli M, Righini A, et al. Magnetic resonance imaging assessment of brain maturation in preterm neonates with punctate white matter lesions. Neuroradiology 2007;49:161-7.

12. Vossough A, Limperopoulos C, Putt ME, et al. Development and validation of a semiquantitative brain maturation score on fetal MR images: initial results. Radiology 2013;268:200-7.

13. Doria V, Arichi T, Edwards DA. Magnetic resonance imaging of the preterm infant brain. Curr Pediatr Rev 2014;10:48-55.

14. Gholipour A, Estroff JA, Barnewolt CE, Connolly SA, Warfield SK. Fetal brain volumetry through MRI volumetric reconstruction and segmentation. Int J Comput Assist Radiol Surg 2011;6:329-39.

15. Maalouf EF, Duggan PJ, Rutherford MA, et al. Magnetic resonance imaging of the brain in a cohort of extremely preterm infants. J Pediatr 1999;135:351-7.

16. Woodward LJ, Anderson PJ, Austin NC, et al. Neonatal MRI to predict neurodevelopmental outcomes in preterm infants. N Engl J Med 2006;355:685-94.

17. Iwata S, Nakamura T, Hizume E, et al. Qualitative brain MRI at term and cognitive outcomes at 9 years after very preterm birth. Pediatrics 2012;129:e1138-47.

18. Reidy N, Morgan A, Thompson DK, et al. Anderson PJ. Impaired language abilities and white matter abnormalities in children born very preterm and/or very low birth weight. J Pediatr 2013;162:719-24.

Cite this article as: Zhu D, Wang M, Feng F, Nan N, Liu Y, Shi J, Mao B. Correlation between clinical features and total maturation score by magnetic resonance imaging in very low birth weight premature infants with brain injury. Ann Palliat Med 2021;10(2):2089-2097. doi: 10.21037/apm-21-55
19. Spittle AJ, Cheong J, Doyle LW, et al. Neonatal white matter abnormality predicts childhood motor impairment in very preterm children. Dev Med Child Neurol 2011;53:1000-6.

20. Cabaj A, Bekiesińska-Figatowska M, Mądzik J. MRI patterns of hypoxic-ischemic brain injury in preterm and full term infants - classical and less common MR findings. Pol J Radiol 2012;77:71-6.

21. Xing S, Li MC, Sun HQ. MRI the total maturational scores (TMS) in the evaluation of brain development and injury in preterm infants. Chinese Community Doctors 2017;32:105-6.

22. Marín-Padilla M. Developmental neuropathology and impact of perinatal brain damage. II: white matter lesions of the neocortex. J Neuropathol Exp Neurol 1997;56:219-35.

23. Van Essen DC. A tension-based theory of morphogenesis and compact wiring in the central nervous system. Nature 1997;385:313-8.

24. Battin MR, Maalouf EF, Counsell SJ, et al. Magnetic resonance imaging of the brain in very preterm infants: visualization of the germinal matrix, early myelination, and cortical folding. Pediatrics 1998;101:957-62.

25. Ramenghi LA, Fumagalli M, Righini A, et al. Magnetic resonance imaging assessment of brain maturation in preterm neonates with punctate white matter lesions. Neuroradiology 2007;49:161-7.

(English Language Editor: C. Betlazar-Maseh) 